\author{
에폭시계 코팅재의 내산열충격 특성에 관한 연구 \\ 이상열 · 윤병두 ${ }^{*}$ \\ 포항1대학 자동차공학과, ${ }^{1}$ 부경대학교 대학원 기계공학과
}

\title{
Study on the characteristics of acid resistance and thermal shock for epoxy coatings
}

\author{
Sang-Yeal LEE and Byoung-Du YUN ${ }^{1 *}$ \\ Department of Automotive Engineering, Pohang College, Gyeongbuk 791-711, Korea \\ ${ }^{1}$ Department of Mechanical Engineering, Graduate School, Pukyong National University, \\ Busan 607-739, Korea
}

This paper was studied on the characteristics of acid resistance and thermal shock for epoxy coatings in the strong acidic environment. The exhaust gas system, such as a air preheater, desulfurization equipment, for industrial boiler is damaged by dew point corrosion. To protect the acid corrosion, the coating using nonmetal was applied. The electrochemical polarization test, acid resistance and thermal shock test for epoxy coatings were carried out. And the acid resistance and thermal shock characteristics, aspect, and electrochemical anti-corrosion characteristics for epoxy coatings in the strong acidic environment were considered. The main results are as followings: As the epoxy glass flake coating by acidic thermal shock was damaged to the crack, blistering and elution etc., the current density of epoxy glass flake coating is high. But the damage of epoxy metal complex coating by acidic thermal shock was not occurred. Therefore the characteristics of acid resistance and thermal shock for epoxy metal complex coating is better than those for epoxy glass flake coating.

Key words : Acid resistance, Thermal shock, Electrochemical polarization test, Epoxy coating

$$
\begin{array}{cl}
\text { 서 론 } & \text { 들 대기오염물질(SOx, } \mathrm{NOx}, \mathrm{CO} \text { 및 } \mathrm{THC} \text { )은 대기 } \\
\text { 화석에너지의 소비량이 증가됨에 따라 유황 } & \text { 중의 수분이나 물에 혼입되거나 산성비에 의해 } \\
\text { 화합물, 질소화합물, 산화물 등의 대기오염물질 } & \text { 하천수나 강물 등에 침투되어 담수를 산성화시 } \\
\text { 배출이 증대됨으로써 수질이 오염되고 있다. 이 } & \text { 켜, } \mathrm{HCl} \text { 및 } \mathrm{Cl}_{2} \text { 등은 담수의 비저항을 낮추는 원 }
\end{array}
$$

\footnotetext{
*Corresponding author: yunbd@pkun.ac.kr, Tel: 82-51-620-1602, Fax: 82-51-620-1602
} 
인이 되기도 한다(Lim et al., 2001; Yasuaki et al., 1991). 또 보일러의 연소가스 중 NOx나 SOx가 생성되면 연소가스 중 수증기의 노점이 상승되 므로 연소가스가 접한 곳에 그 노점보다 낮은 곳 이 있으면 그 곳에 연소가스 중의 수증기가 응결 하고 $\mathrm{NOx}$ 나 $\mathrm{SOx}$ 가 용입함으로 심한 산부식(노 점부식, dew point corrosion)을 일으킨다(Jeon, 1989). 특히, 산업용 보일러에서 공기예열기, 절 탄기, 탈황장치 등의 연도시스템은 산노점 부식 을 일으키며, 화력발전소의 절탄기 및 가스콘덴 싱 보일러 응축기로부터 drain된 응축수의 $\mathrm{pH}$ 는 -0.9 로 강산성 인 경우도 있다(Lee, 1997).

이러한 강산성 환경은 탄소강재의 부식을 심 화시킬 뿐만 아니라 스테인리스강재를 부식시 켜 두께감소를 초래하며, 공식이나 극간부식 등 을 발생시킨다. 그러므로 보일러의 연도시스템 에 내식성, 내마모성, 경제성 등의 측면에서 금 속계나 비금속계 코팅(coating)이나 라이닝 (lining)이 실시되고 있으나, 보일러 연도시스템 의 코팅재에 대한 산부식특성에 관한 정량적인 연구는 거의 찾아 볼 수 없다(Mitsuyori et al., 1989; Takashi et al., 1986).

따라서 본 연구에서는 강산성 환경 중에서 에 폭시계 코팅재의 내산열충격 특성에 관한 연구 를 하기 위하여, 에폭시(epoxy)계 글라스 플레이 크(glass flake) 코팅재 및 메탈(metal) 복합 코팅 재에 대해서 강산성환경 중에서 내산열충격 실 험과 동시에 전기화학적 분극시험을 실시하였 다. 이러한 실험결과를 토대로 하여, 에폭시계 글라스 플레이크 코팅재 및 메탈 복합 코팅재의 내산열충격 특성을 전기화학적 분극을 접목하 여 고찰하였다.

\section{재료 및 방법}

시험 재료

본 실험에 사용된 시험편의 모재인 일반구조 용 압연강재(SS 400)의 화학적 성분 및 기계적 특성을 Table 1에 나타내었다. 또한 본 실험에 사
용된 코팅재는 시판되고 있는 에폭시계 글라스 플레이크 코팅재 및 메탈 복합 코팅재로 하였으 며, 그 화학적 성분은 Table 2 와 Table 3 과 같다.

Table 1. Chemical compositions and mechanical properties of SS 400

\begin{tabular}{|c|c|c|c|c|c|c|}
\hline $\begin{array}{l}\text { Chemical } \\
\text { composition } \\
\text { (wt \%) }\end{array}$ & $\begin{array}{c}\mathrm{C} \\
0.16\end{array}$ & $\begin{array}{c}\mathrm{Si} \\
0.06\end{array}$ & $\begin{array}{l}\mathrm{Mn} \\
0.58\end{array}$ & $\begin{array}{c}\mathrm{P} \\
0.018\end{array}$ & $\begin{array}{c}\mathrm{S} \\
0.01\end{array}$ & $\begin{array}{c}\mathrm{Cu} \\
0.10\end{array}$ \\
\hline $\begin{array}{c}\text { Mechanical } \\
\text { properties }\end{array}$ & \multicolumn{2}{|c|}{$\begin{array}{l}\text { Tensile strength } \\
\text { (MPa) } \\
426\end{array}$} & \multicolumn{2}{|c|}{$\begin{array}{l}\text { Yield strength } \\
\text { (MPa) } \\
270\end{array}$} & \multicolumn{2}{|c|}{$\begin{array}{c}\text { Elongation } \\
(\%) \\
25\end{array}$} \\
\hline
\end{tabular}

Table 2. Chemical compositions of epoxy glass flake coating

\begin{tabular}{lc}
\hline $\begin{array}{l}\text { Chemical } \\
\text { compositions }\end{array}$ & $\begin{array}{c}\text { Weight } \\
\text { percent }(\%)\end{array}$ \\
\hline Epoxy resin & 74 \\
Titanium dioxide & 8 \\
Glass flake & 16 \\
Reactive ingredients & 2 \\
\hline
\end{tabular}

Table 3. Chemical compositions of epoxy metal complex coating

\begin{tabular}{lc}
\hline $\begin{array}{l}\text { Chemical } \\
\text { compositions }\end{array}$ & $\begin{array}{c}\text { Weight } \\
\text { percent }(\%)\end{array}$ \\
\hline Epoxy resin & 70 \\
Alumina & 7 \\
Titanium dioxide & 13 \\
Zirconium & 8 \\
Reactive ingredients & 2 \\
\hline
\end{tabular}

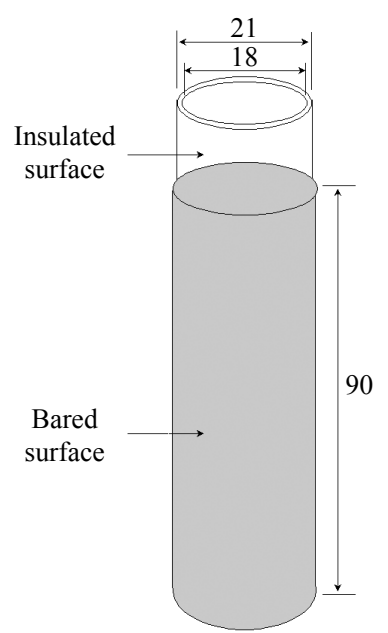

Fig. 1. Configuration and dimension of coating steel specimen(unit: $\mathbf{m m}$ ). 
Table 1에 나타낸 것과 같은 화학적 성분 및 기 계적 특성을 가진 일반구조용 압연강관재인 $\mathrm{SS}$ 400 시험재료로부터 절취하여 시험편을 제작 가공하였다. 이 시험편의 전표면에 sandblast 한 후, 아세톤으로 탈지하여 건조시킨 다음, 에폭시 계 글라스 플레이크 코팅 및 메탈 복합 코팅을 실시하여 Fig.1과 같은 코팅강재 시험편을 제작 하였고, 유효노출면적은 $33 \mathrm{~cm}^{2}$ 로 하였다. 여기 서, 에폭시계 글라스 플레이크 코팅재 및 메탈 복합 코팅재의 두께는 $0.7 \mathrm{~mm}$ 로 탄소강관에 일 정하게 코팅하였다.

\section{실험방법}

코팅강재의 내산열충격 실험은 연도시스템에 대한 코팅재의 산저항성시험(ASTM D 6137 97)를 기준으로 하여 실험하였으며(ASTM, 2004), 내산열충격 실험하기 전 전기화학적 분 극실험에 의해 강산성환경 중에서 코팅재 시험 편의 균열, pin hole 등 결함에 대한 실험을 실시 하였다.

본 연구에서 내산열충격 실험 및 전기화학적 분극실험의 부식환경 조건은 증류수 중에 황산 $\left(\mathrm{H}_{2} \mathrm{SO}_{4}\right)$ 을 소량씩 첨가하여 강산성인 황산 $20 \%$ 수용액으로 각각 일정하게 유지하고, 각 부식용 액의 온도는 가열코일이 부착된 oil bath에 실리 콘 오일을 주입하였으며, oil bath에 부식환경조 를 설치하였다. 부식용액의 온도는 온도감지기 를 설치하여, 온도를 $25 \pm 11^{\circ} \mathrm{C}$ 로 일정하게 유지 하였다.

내산열충격 실험은 에폭시계 글라스 플레이 크 코팅재 및 메탈 복합 코팅재를 $20 \% \mathrm{H}_{2} \mathrm{SO}_{4}$ 수 용액 $\left(25 \pm 1^{\circ} \mathrm{C}\right)$ 중에서 24 시간 침지 후, $177^{\circ} \mathrm{C}$ 로 예열된 전기로에서 16 시간 건조하였고, 내산열 충격 실험 후 시험편의 표면양상을 관찰 - 조사 하였다. 좀 더 정성적으로 분석하기 위하여 전기 화학적 양극분극실험을 실시하였다.

본 실험에 사용된 실험장치는 다른 부식의 평 가법 보다 실험시간이 짧게 되고, 비파괴적으로
실시할 수 있는 전기화학적 분극실험 장치 (Model 273A Potentiostat/Galvanostat, EG \& G)이 다. 전기화학 분극시험은 부식환경조 중에서 시 험편을 에폭시계 글라스 플레이크 코팅재 및 메 탈 복합 코팅재로 하고, 기준전극은 포화칼로멜 전극, 보조전극은 고밀도 탄소봉으로 하였다.

\section{결과 및 고찰}

에폭시계 글라스 플레이크 코팅재의 내산열충 격 거동

Fig. 2는 $20 \%$ 황산 수용액 중에서 에폭시계 글 라스 플레이크 코팅재에 대해 내산열충격 실험 하기 전과 내산열충격 실험을 반복적으로 실시 하였을 때의 각 cycle의 양극분극곡선을 나타낸 것이다.

내산열충격 실험하기 전의 에폭시계 글라스 플 레이크 코팅재의 부식전류밀도는 개로전위(open circuit potential)하에서 $1 \times 10^{-10}-2 \times 10^{-9} \mathrm{~A} / \mathrm{cm}^{2}$ 로 나타나고, 양극전위를 $2000 \mathrm{mV} / \mathrm{SCE}$ 로 인가하는 데도 불구하고 개로전위하에서와 같은 부식전류 밀도를 나타내고 있음을 알 수 있다. 이와 같은 현 상은 noise와 같은 전류밀도가 나타나 공학단위 에서 무시할 수 있으므로(William, 1994) 에폭시 계 글라스 플레이크 코팅재의 균열이나 pin hole

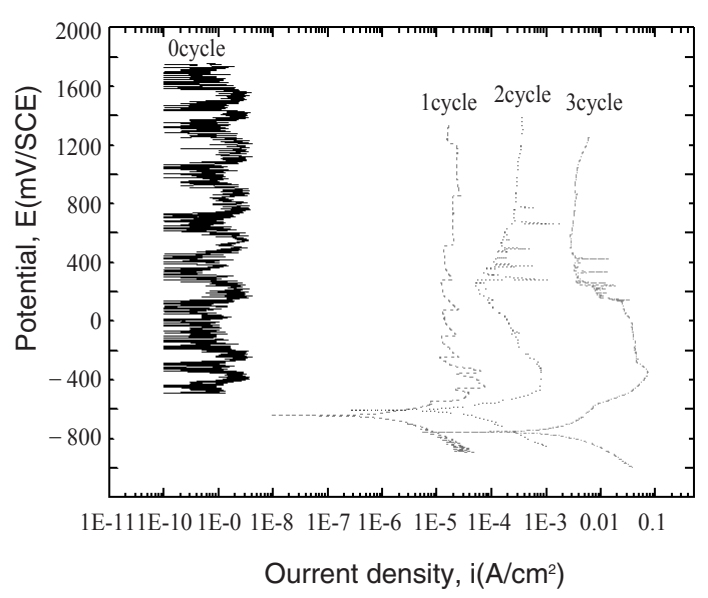

Fig. 2. Anodic polarization curves of epoxy glass flake coating for SS 400 after acid resistance test in $20 \%$ $\mathrm{H}_{2} \mathrm{SO}_{4}$ solution at $25^{\circ} \mathrm{C}$. 
등의 결함이 없는 것으로 추정된다.

그러나 내산열충격 실험 1cycle에서 에폭시계 글라스 플레이크 코팅재의 부식전류밀도는 개 로전위하에서 $2 \times 10^{-6} \mathrm{~A} / \mathrm{cm}^{2}$ 로 내산열충격 실험 전 0 cycle의 부식전류밀도보다 높게 배류되고 양극전위가 상승함에 따라 부식전류밀도가 증 가하다가 부동태 현상을 나타내고 있다. 또한 내 산열충격 실험 2 및 3 cycle에서 부식전류밀도가 내산열충격 실험 $1 \mathrm{cycle}$ 의 부식전류밀도보다 더 욱 높게 배류되는 경향이지만, 이들 역시 부동태 현상을 나타내고 있다. 이와 같이 내산열충격 실 험 1,2 및 3cycle에서 양극전위가 상승하면서 부 식전류밀도가 증가하게 되는 이유는 코팅재중 의 글라스 플레이크가 열충격에 의해 수축과 팽 창의 반복에 의해 코팅재 표면에 균열이나 탈리 등의 손상을 일으키기 때문인 것으로 사료된다 (Kim, 1991). 또한 부동태 현상을 나타내는 이유 는 에폭시계 글라스 플레이크 코팅재의 화학적 조성에서 Titanium dioxide $\left(\mathrm{TiO}_{2}\right)$ 가 부동태화제 로 작용하기 때문인 것으로 사료된다(Joseph, 2000).

에폭시계 글라스 플레이크 코팅재의 내산열충 격 양상

Fig. 3은 20\% 황산 수용액 중에서 에폭시계 글 라스 플레이크 코팅재에 대해 내산열충격 실험 하기 전 에폭시계 글라스 플레이크 코팅재의 표

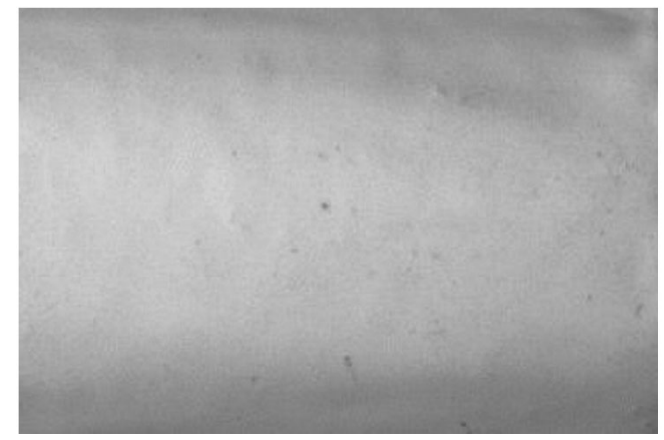

Fig. 3. Appearance of epoxy glass flake coating for SS 400 before acid resistance test in $20 \% \mathrm{H}_{2} \mathrm{SO}_{4}$ solution.
면 양상을 나타낸 것이다.

Fig. 3 에 보인 바와 같이 에폭시계 글라스 플레 이크 코팅재의 결함은 가시적으로 나타나지 않 고 있다. 즉, Fig. 2의 내산열충격 실험전인 0cycle 에서 보는 바와 같이 부식전류밀도가 거의 나타 나지 않고, noise로 추정되는 전류가 나타나고 있 으므로 에폭시계 글라스 플레이크 코팅재의 균 열이나 pin hole 등의 초기 결함은 없는 것으로 판 단된다.

Fig. 4는 $20 \%$ 황산 수용액 중에서 에폭시계 글 라스 플레이크 코팅재에 대해 내산열충격 실험 1 cycle 실시하였을 때의 에폭시계 글라스 플레 이크 코팅재의 표면 손상양상을 나타낸 것이다.

$1 \mathrm{cycle}$ 내산열충격 실험에 의해 에폭시계 글 라스 플레이크 코팅재 표면은 균열, blistering 및 탈리 등의 손상이 일어나고 있음을 알 수 있다. 이러한 심한 코팅재 표면의 손상은 Fig. 2 의 분 극거동에서 에폭시계 글라스 플레이크 코팅재 의 부식전류밀도가 내산열충격 실험전의 부식 전류밀도보다 더 높게 배류되는 것이 그 원인인 것으로 판단된다.

Fig. 5 는 $20 \%$ 황산 수용액 중에서 에폭시계 글 라스 플레이크 코팅재에 대해 내산열충격 실험 2cycle 실시하였을 때의 에폭시계 글라스 플레 이크 코팅재의 표면 손상양상을 나타낸 것이다.

2cycle 내산열충격 실험 후의 표면양상은 Fig.

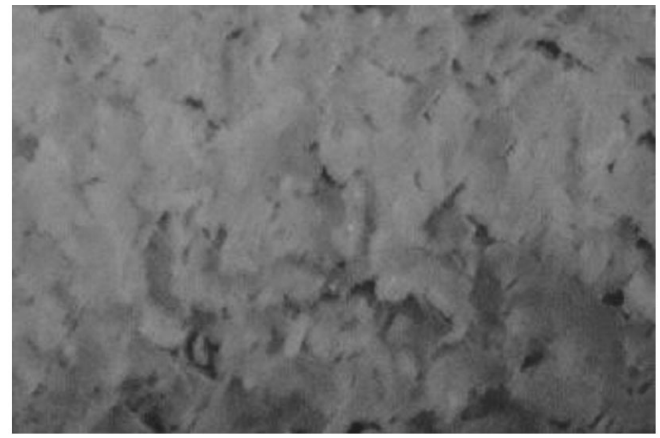

Fig. 4 Damage appearance of epoxy glass flake coating for SS 400 after 1 cycle acid resistance test in $20 \% \mathrm{H}_{2} \mathrm{SO}_{4}$ solution. 
4 의 1 cycle 내산열충격 실험보다 에폭시계 글라 스 플레이크 코팅재의 균열, blistering 및 탈리 등 으로 인해 더 심한 손상이 일어나고 있음을 알 수 있다. 이와 같은 심한 코팅재의 표면 손상은 Fig. 2의 분극거동에서 고찰한 바와 같이 2 cycle 내산열충격 실험에서 에폭시계 글라스 플레이 크 코팅재의 부식전류밀도가 1cycle 내산열충격 실험의 부식전류밀도 보다 더욱 높게 배류되는 것이 그 원인인 것으로 판단된다..

Fig. 6은 20\% 황산 수용액 중에서 에폭시계 글 라스 플레이크 코팅재에 대해 내산열충격 실험 3 cycle 실시하였을 때의 에폭시계 글라스 플레 이크 코팅재의 표면 손상양상을 나타낸 것이다. 3 cycle 내산열충격에 의해 에폭시계 글라스

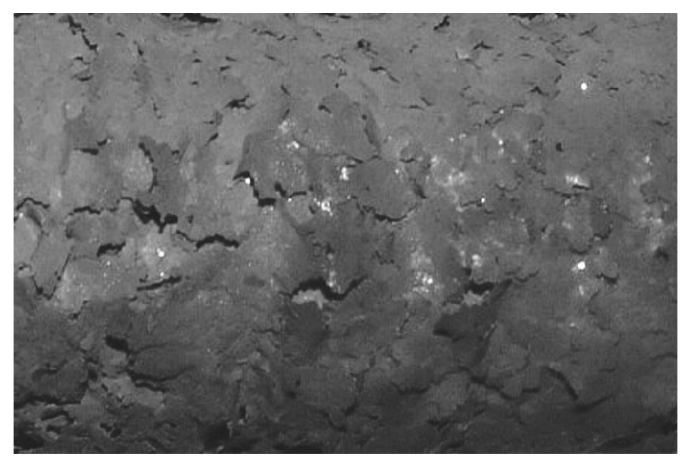

Fig. 5 Damage appearance of epoxy glass flake coating for $\mathrm{SS} 400$ after 2 cycle acid resistance test in $20 \% \mathrm{H}_{2} \mathrm{SO}_{4}$ solution.

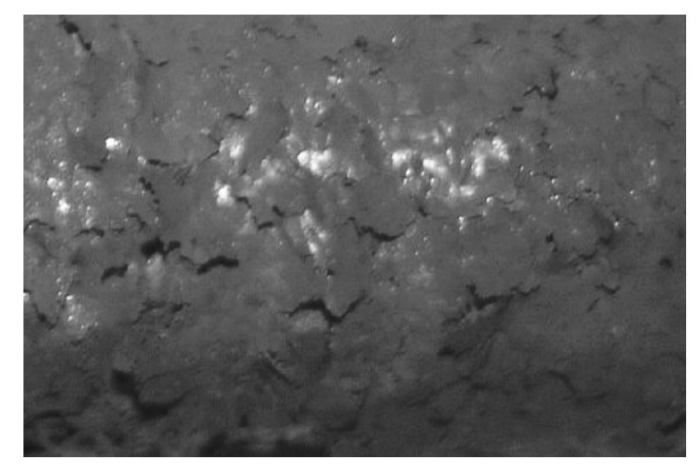

Fig. 6. Damage appearance of epoxy glass flake coating for $\mathrm{SS} 400$ after 3 cycle acid resistance test in $20 \% \mathrm{H}_{2} \mathrm{SO}_{4}$ solution.
플레이크 코팅재 표면의 blistering 부위 및 균열 부위가 용출 및 탈리현상이 심하게 일어나고 있 음을 알 수 있다. 이러한 심한 용출 및 탈리 현상 이 일어나는 이유는 강산에 의해 코팅재 표면에 발생된 blistering이나 균열부위가 용해되어 탈리 되기 때문인 것으로 사료된다(Sheir et al., 1994).

에폭시계 메탈 복합 코팅재의 내산열충격 거동

Fig. 7은 20\% 황산 수용액 중에서 에폭시계 메 탈 복합 코팅재에 대해 내산열충격 실험하기 전 과 내산열충격 실험을 반복적으로 실시하였을 때 의 각 cycle의 양극분극곡선(개로전위로부터 양 극전위 $2000 \mathrm{mV} / \mathrm{SCE}$ 로 인가)을 나타낸 것이다.

내산열충격을 실험하기 전이나 내산열충격 시 험 1,2 및 3cycle 후의 에폭시계 메탈 복합 코팅재 의 부식전류밀도는 개로전위하에서 $1 \times 10^{-10}-2$ $\times 10^{-9} \mathrm{~A} / \mathrm{cm}^{2}$ 로 나타나고, 양극전 위를 2000 $\mathrm{mV} / \mathrm{SCE}$ 로 인가하는데도 불구하고 개로전위하 에서와 같은 부식전류밀도를 나타내고 있음을 알 수 있다. 이와 같이 개로 전위로부터 $2000 \mathrm{mV} / \mathrm{SCE}$ 로 인가하는데도 불구하고 부식전 류밀도는 $1 \times 10^{-10}-2 \times 10^{-9} \mathrm{~A} / \mathrm{cm}^{2}$ 로 나타남으로 써 공학단위에서 무시할 수 있으므로 에폭시계 메탈 복합 코팅재의 내산열충격실험 전에 균열,

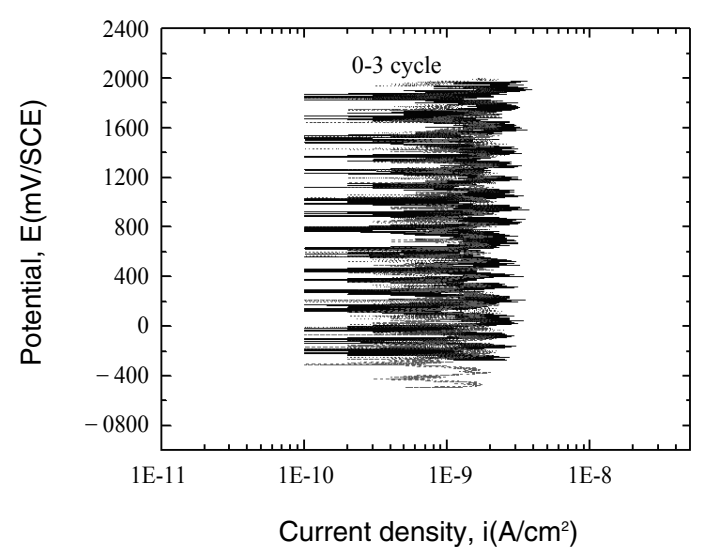

Fig. 7. Anodic polarization curves of epoxy metal complex coating for SS 400 after acid resistance test in $20 \% \mathrm{H}_{2} \mathrm{SO}_{4}$ solution at $25^{\circ} \mathrm{C}$. 
pin hole 등의 결함이 없으며, 1, 2 및 3cycle 내산 열충격실험 후에도 코팅재의 균열이나 blistering 등의 산열충격 손상이 없는 것으로 추정된다.

에폭시계 메탈 복합 코팅재의 내산열충격 양상

Fig. 8 은 $20 \%$ 황산 수용액 중에서 에폭시계 메 탈 복합 코팅재에 대해 내산열충격을 실험하기 전 코팅재의 표면 양상을 나타낸 것이다.

Fig. 8에 보인 바와 같이 에폭시계 메탈 복합 코팅재의 결함은 가시적으로 나타나지 않고 있 으며, Fig. 7의 내산열충격 실험전인 0cycle에서 보는 바와 같이 부식전류밀도가 거의 배류되지 않고, noise로 추정되는 전류가 나타나고 있으므 로 에폭시계 메탈 복합 코팅재에 균열이나 pin hole 등의 미세한 결함도 없는 것으로 판단된다.

Fig. 9는 20\% 황산 수용액 중에서 에폭시계 메 탈 복합 코팅재에 대해 내산열충격 실험 $1 \mathrm{cycle}$, 2 cycle 및 3 cycle 까지 실시하였을 때의 각 cycle 에서 에폭시계 메탈 복합 코팅재의 표면 손상 양 상을 나타낸 것이다.

Fig. 9의 (a) 1cycle, (b) 2cycle 및 (c) 3cycle 내산 열충격 실험의 표면양상은 Fig. 8의 실험전 표면 양상과 가시적인 변화가 거의 없다. 또한 Fig. 7 의 1,2 및 3 cycle 분극거동에 보인바와 같이 부 식전류밀도가 거의 배류되지 않고, noise로 추정 되는 전류가 나타나고 있으므로 산열충격에 의 한 에폭시계 메탈 복합 코팅재의 손상이 없는 것

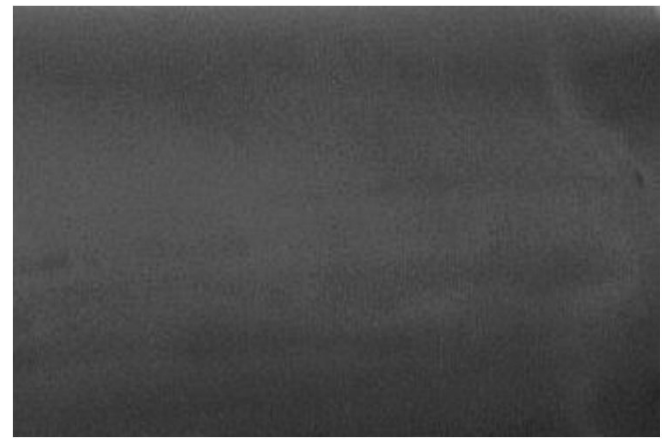

Fig. 8. Appearance of epoxy metal complex coating for SS 400 before acid resistance test in $20 \% \mathrm{H}_{2} \mathrm{SO}_{4}$ solution.
으로 판단된다. 이와 같이 내산열충격에 의해 메 탈 복합 코팅재의 손상이 일어나지 않는 이유는 금속인 지르코늄의 내식성과 고온강도가 우수 한 요인과 세라믹계인 알루미나의 열충격성과

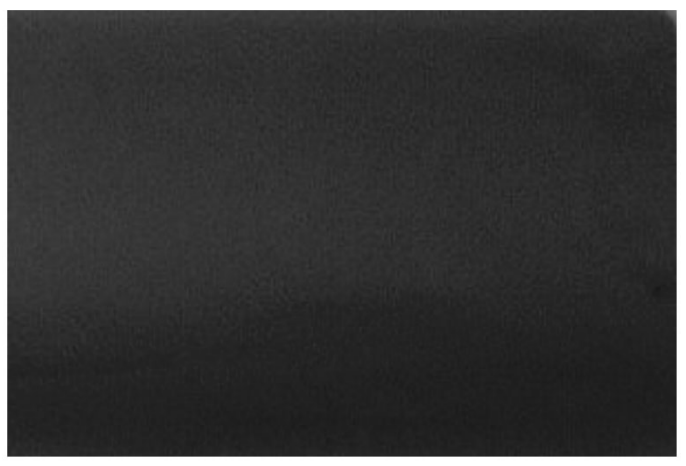

(a) 1 cycle

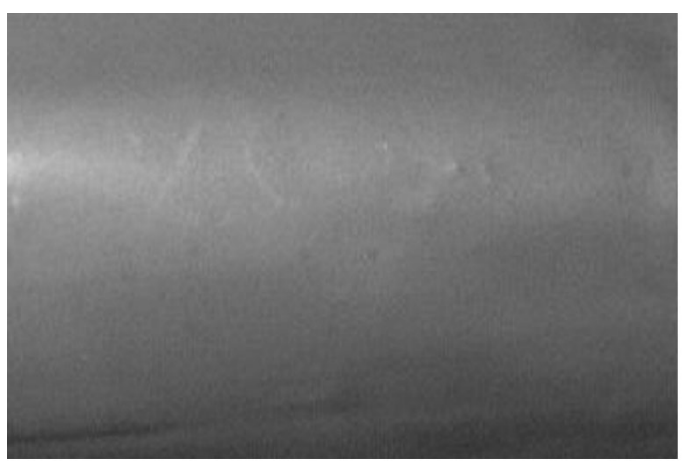

(b) 2 cycle

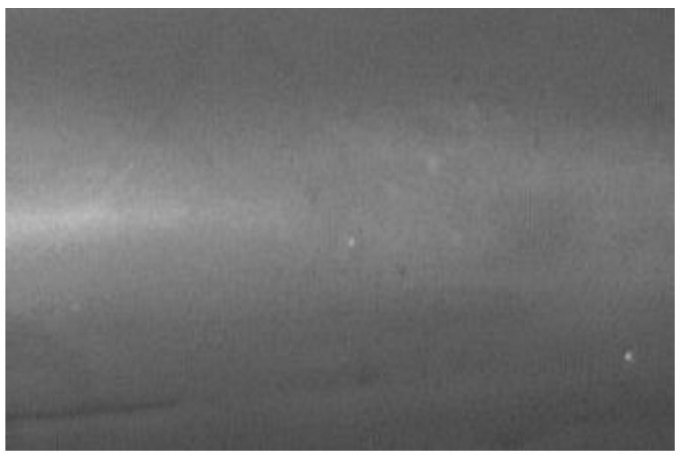

(c) 3 cycle

Fig. 9. Damage appearance of epoxy metal complex coating for SS 400 after 1, 2 and 3 cycle acid resistance test in $20 \% \mathrm{H}_{2} \mathrm{SO}_{4}$ solution. 
내산성이 우수한 요인의 시너지 효과(synergy effect) 때문인 것으로 사료된다(Joseph, 2000; Song et al., 1996).

\section{각종 코팅강재의 내산열충격 특성비교}

Fig. 10은 20\% 황산 수용액 중에서 3회 내산열 충격 실험 후 에폭시계 글라스 플레이크 코팅재 및 메탈 복합 코팅재의 양극분극곡선을 정리하 여 나타낸 것이다.

에폭시계 메탈 복합 코팅재의 부식전류밀도 는 개로전위하에서나 양극전위 $2000 \mathrm{mV} / \mathrm{SCE}$ 로 인가하는데도 불구하고 $1 \times 10^{-10}-2 \times 10^{-9} \mathrm{~A} / \mathrm{cm}^{2}$ 로 나타나고 있다.

그러나 에폭시계 글라스 플레이크 코팅재의 양극분극거동은 개로전위에서나 양극전위가 높 아지면서 부식전류밀도는 에폭시계 메탈 복합 코팅재의 부식전류밀도보다 매우 높게 나타내 고 있다. 그러므로 산열충격에 의한 코팅재 표면 의 손상양상이나 전기화학적 양극분극거동에서 에폭시계 메탈 복합 코팅재의 내산열충격특성 은 에폭시계 글라스 플레이크 코팅재의 내산열 충격특성보다 더 우수함을 알 수 있다.

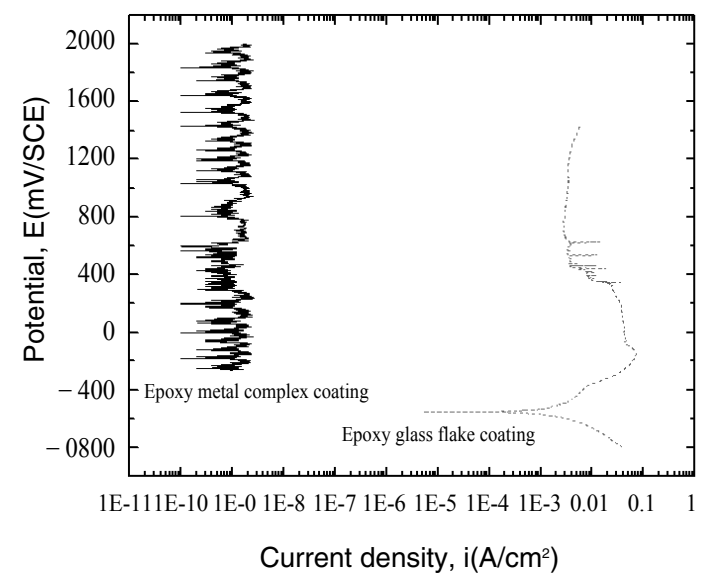

Fig. 10. Anodic polarization curves of epoxy glass flake and metal complex coating for SS 400 after 3 cycle acid resistance test in $20 \% \mathrm{H}_{2} \mathrm{SO}_{4}$ solution.

\section{결 론}

강산성 환경 중에서 에폭시계 글라스 플레이 크 코팅재 및 메탈 복합 코팅재의 내산열충격 특 성에 관하여 연구한 결과 다음과 같다. 산열충격 에 의해 에폭시계 글라스 플레이크 코팅재는 균 열, blistering, 탈리 및 용출 등의 손상이 일어남 으로써 부식전류밀도는 높게 배류되고 있다. 그 러나 에폭시계 메탈 복합 코팅재의 내산열충격 특성은 산열충격에 의해 손상이 일어나지 않음 으로써 에폭시계 글라스 플레이크 코팅재의 내 산열충격특성보다 더 우수하다.

\section{참고문헌}

ASTM INTERNATIONAL, 2004. Standard test method for sulfuric acid resistance of polymer linings for flue gas desulfurization Systems. D6137-97, pp. $1-3$.

Jeon, D.H., 1989. Practical anti-corrosion engineering. TaeHwa publishing Co., pp. $172-173$.

Joseph, R.D., 2000, Corrosion understanding the basics. ASM international, p. 279, p. 287.

Kim, C.Y., 1991. Properties and application of glass. DaeGwang Co., p. 92.

Lee, Y.H., 1997. Anticorrosive data book, Korea institute of construction anti corrosive technology. pp. 251 257.

Lim, U.H., S.J. Kim, J.H. Hwang, D.Y. Yun, 2001. The study on the behavior of corrosion Al-alloy shell for cooler. Autumn conference of KSPSE, 209-210.

Mitsuyori, A., T. Tooru and H. Shiro, 1989. Mass transport and delamination of coated steels during under-film corrosion. ZAIRYO-TO-KANKYO. Japan, 38(8), $429-436$.

Sheir, L.L., R.A. Jarman, 1994. Corrosion volume 2. Butterworth Heinemann Ltd., pp. 14:43 - 14:44.

Song, W. and K.J. Kim, 1996. A study on the physical properties of alumina with oxides addition and its corrosion behavior in alkaline solution. CSSK 25(2), 192.

Takashi, Y., O. Mitsuyuki, M. Takeo, I. Yoshitaka and H. 
Kiyoaki, 1986. ZAIRYO-TO-KANKYO. Japan, $35(1), 3-5$.

William, H.H. and H.C. Charles, 1994. Calcareous deposits on metal surfaces in seawater. Corrosion. NACE, 40(11), $609-618$.

William. S.T., 1994. An instruction to electrochemical corrosion testing for practicing engineers and scientists. Clair, pp. $58-61$.

Yausaki, M. and T. Norimichi, 1991. Global acidic environmental pollution and materials damage. ZAIRYO-TO-KANKYO. Japan, 40(9), 619 - 629.

2007년 7월 31일 접수

2007년 9월 20일 수리 